\title{
Design of the Multi-Energy Complementary Distributed Energy System for Towns
}

\author{
Tieyin Zhang', Weihan Song1, Shubao Wang1, Yuegang Wang1, Yukun Chen ${ }^{2}$ \\ ${ }^{1}$ Dahua Engineering Management Group Company Limited, Beijing, China \\ ${ }^{2}$ Department of Electrical Engineering, Tsinghua University, Beijing, China \\ Email: chenyk20@mails.tsinghua.edu.cn
}

How to cite this paper: Zhang, T.Y., Song, W.H., Wang, S.B., Wang, Y.G. and Chen, Y.K. (2021) Design of the Multi-Energy Complementary Distributed Energy System for Towns. Journal of Power and Energy Engineering, 9, 53-60.

https://doi.org/10.4236/jpee.2021.94004

Received: February 26, 2021

Accepted: April 16, 2021

Published: April 19, 2021

Copyright $\odot 2021$ by author(s) and Scientific Research Publishing Inc. This work is licensed under the Creative Commons Attribution International License (CC BY 4.0).

http://creativecommons.org/licenses/by/4.0/

\section{Open Access}

\begin{abstract}
The multi-energy complementary distributed energy system (MCDES) covers a variety of energy forms, involves complex operation modes, and contains a wealth of control equipment and coupling links. It can realize the complementary and efficient use of different types of energy, which is the basic component of the physical layer of the Energy Internet. In this paper, aiming at the demand of the energy application for towns, a distributed energy system based on multi-energy complementary is constructed. Firstly, the supply condition of the distributed energy for the demonstration project is analyzed, and the architecture of the multi-energy complementary distributed energy system is established. Then the regulation strategy of the multi-energy complementary distributed energy system is proposed. Finally, an overall system scheme for the multi-energy complementary distributed energy system suitable for towns is developed, which provides a solid foundation for the development and promotion of the multi-energy complementary distributed energy system.
\end{abstract}

\section{Keywords}

Multi-Energy Complementary, Distributed Energy System, System Scheme

\section{Introduction}

The distributed energy system (DES) is the basic component of the physical layer for the energy Internet, which can realize the complementary and efficient use of different types of energy. From the source side, DES includes different forms of energy such as cold, heat, electricity and gas; from the grid side, DES includes different energy network architectures such as cooling grid, heating grid, power grid and gas grid; from the storage side, DES includes electricity 
storage, heat storage, cold storage and so on; from the load side, DES includes not only the main power load, but also the heating load and cooling load [1] [2] [3] [4] [5].

In the research on DES, the University of Manchester in the United Kingdom has developed a distributed energy system with an electric-heat-gas system and a user interaction platform, which achieves the functions of energy consumption, energy saving and demand response to user terminals [6]. By encouraging the construction of E-Energy projects, Germany focuses on the integration of energy and information systems, and adopts digital networks to realize the safe supply, efficient utilization and climate protection of power generation [7]. Japan established the Japan Smart Community Alliance as early as 2010, focusing on the construction of demonstration projects for smart community technologies and distributed energy systems [8]. In recent years, DES research has become a trend in China. Aiming at building an intelligent industrial demonstration zone, Guangzhou Mingzhu Industrial Zone has constructed a cooling-heating-electricity-gas distributed energy system to improve energy utilization [9]. The Urban Energy Internet demonstration project in Yanqing, Beijing aims to build a regional distributed energy system that supports a high penetration rate [10]. In conclusion, the planning and design, optimization and coordination of the multi-energy complementary distributed energy system (MCDES) have been widely studied, but there is no overall design scheme for the distributed energy system for towns.

This paper comprehensively uses a variety of energy production methods, energy storage equipment and the principle of photothermal and chemical complementarity to construct the urban multi-energy complementary distributed energy system project in Zhangjiakou [11]. And an overall scheme of MCDES suitable for towns is proposed, which has laid a solid technical foundation and practical experience for realizing the large-scale distributed energy system.

\section{Load Profile of Distributed Energy System}

\subsection{Load Characteristics}

Zhangjiakou is a prefecture level city in Hebei Province, which is rich in new energy resources. The main load of the multi-energy complementary distributed energy system project is Zhangjiakou Dahuajianguo Hotel. The hotel mainly receives group catering, accommodation, and conferences. The arrival time of guests is uncertain, which causes unstable and fluctuating loads. Therefore, through long-term observation and recording, the law and characteristics of the distributed energy system load can be obtained.

\subsection{Load Composition Analysis}

At present, the hotel mainly relies on $3000 \mathrm{~m}^{3}$ solar energy for cross-season heat storage and heating. Due to insufficient heating capacity, a $2 \mathrm{~T} / \mathrm{h}$ heating electric boiler (actually $1.5 \mathrm{~T} / \mathrm{h}$ ) and a $1 \mathrm{~T} / \mathrm{h}$ hot water electric boiler (actually $0.5 \mathrm{~T} / \mathrm{h}$ ), 
which also provides hot water for swimming pools, are used to supplement heat. The heating demand in winter and the cooling demand in summer lead to an increase in power consumption. Other electric loads in the hotel include guest rooms, restaurants, and meeting rooms.

\subsection{Load Curve}

The operating current of the main transformer is $1500-1700 \mathrm{~A}$ in winter and $600-800 \mathrm{~A}$ in summer, as shown in Figure 1.

The hot water consumption is $2000-2400 \mathrm{kWh} /$ day in winter and $1000-2000$ $\mathrm{kWh}$ /day in summer, as shown in Figure 2.

\section{Design of the Multi-Energy Complementary Distributed Energy System}

Figure 3 shows the overall scheme of multi-energy complementary distributed energy system in Zhangjiakou [12]. The system is composed of multiple multi-energy complementary units, including parabolic trough photothermal subsystem, waste heat recovery and heat pump integrated subsystem, hundred $\mathrm{kW}$-level wind energy heating subsystem, electrochemical electricity storage subsystem and so on.

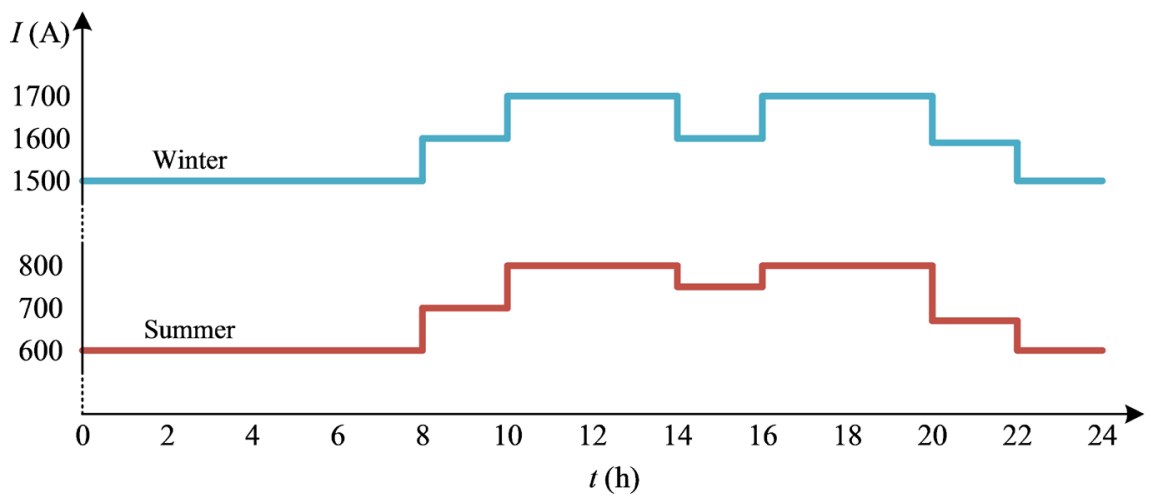

Figure 1. Operating current of main transformer.

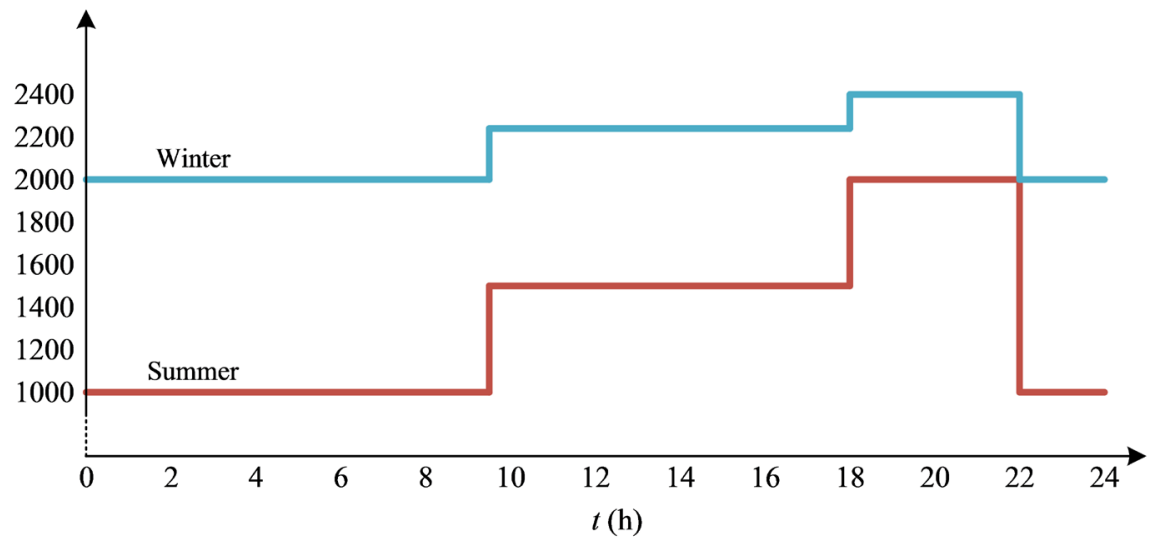

Figure 2. Consumption of hot water. 


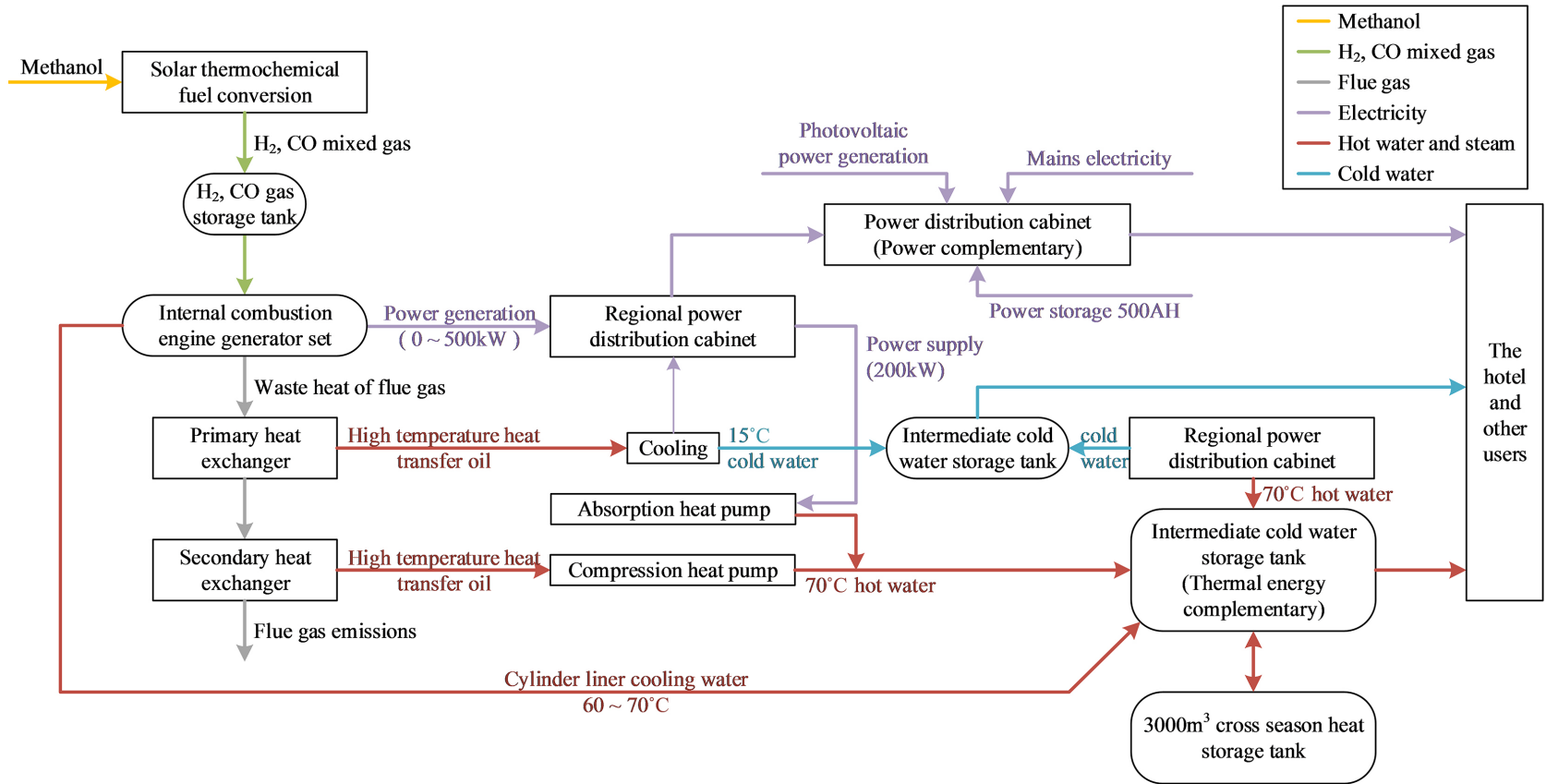

Figure 3. The overall scheme of MCDES in Zhangjiakou.

\subsection{Trough Photothermal Subsystem}

In order to achieve multi-energy complementarity, MCDES uses a trough photothermal system to decompose methanol into $\mathrm{H}_{2}$ and $\mathrm{CO}$ syngas, drives a 500 $\mathrm{kW}$ internal combustion generator set, and provides high-efficiency power and heat. The specific technical parameters are as follows:

- Electricity: a $500 \mathrm{~kW}$ internal combustion generator set, generating power of $500 \mathrm{~kW}$ and efficiency of $35.1 \%$;

- Thermal energy of power exhaust: $250^{\circ} \mathrm{C}, 211.4 \mathrm{~kW} ; 170^{\circ} \mathrm{C}, 293.3 \mathrm{~kW} ; 90^{\circ} \mathrm{C}$, $373.9 \mathrm{~kW}$;

- Cylinder jacket water heat energy: $70^{\circ} \mathrm{C}-90^{\circ} \mathrm{C}, 369.25 \mathrm{~kW}$.

\subsection{Waste Heat Recovery and Heat Pump Integrated Subsystem}

In order to realize the cascade utilization of heat energy, the power waste heat depth cascade utilization system is designed, and a low-grade waste heat driven full heat recovery heat pump and an efficient compression heat pump are developed. The specific technical parameters are as follows:

- Electricity: cooling and generator power is $4.5 \mathrm{~kW}$;

- Refrigeration inlet: water temperature $<20^{\circ} \mathrm{C}$, flow rate $>15 \mathrm{~m}^{3} / \mathrm{h}$;

- Absorption heat pump unit: temperature $<70^{\circ} \mathrm{C}$, heating capacity is 210.5 $\mathrm{kW}$;

- Four-stage compression heat pump unit: the heating temperature $<70^{\circ} \mathrm{C}$, the heating capacity is $249 \mathrm{~kW}$, and the required power is $200 \mathrm{~kW}$.

\subsection{Hundred kW-Level Wind Energy Heating Subsystem}

A hundred kW-level wind energy direct heating (cooling) system is designed, 
which can meet the needs of winter heating and summer cooling for $3000 \mathrm{~m}^{2}$ buildings in towns. The specific technical parameters are as follows:

- Heating capacity $>300 \mathrm{~kW}$, wind energy utilization factor $>42 \%$;

- Hot water outlet temperature $>60^{\circ} \mathrm{C}$, cold water outlet temperature $5^{\circ} \mathrm{C}$ $10^{\circ} \mathrm{C}$.

\subsection{Solar Cross Season Heat Storage Subsystem}

Aiming at supplying heat to $3000 \mathrm{~m}^{2}$ buildings in towns, solar tower heliostat technology is used to gather heat, which includes 66 heliostats with a total area of $760 \mathrm{~m}^{2}$, a heat absorber with a total height of $22.313 \mathrm{~m}$, and a cylindrical concrete structure heat storage pool with an effective volume of $3000 \mathrm{~m}^{3}$.

\subsection{Distributed Photovoltaic Power Generation Subsystem}

In the multi-energy complementary distributed energy system, a $1 \mathrm{MW}$ polysilicon photovoltaic power generation system is designed.

\subsection{Electrochemical Storage Subsystem}

In the multi-energy complementary distributed energy system, a $500 \mathrm{AH}$ storage system is designed. In addition, a smart control and display system is built for MCDES.

\subsection{Design of Energy Output}

Based on the distributed energy system project designed above, Figure 4 shows the power generation situation in winter and Figure 5 shows the heating situation in winter

As can be seen from Figure 4 and Figure 5, due to the uncertainty of hotel load and the discontinuity of distributed energy, in addition to the inability to carry out active control, there are also intermittent situations, which leads to insufficient energy supply as well as the waste of oversupply. Therefore, energy storage is a very critical link. The establishment of a $3000 \mathrm{~m}^{3}$ cross-season thermal storage cistern provides the necessary guarantee for the full and stable heat use of the system.

\section{Control Strategy of the Multi-Energy Complementary Distributed Energy System}

\subsection{Control Method Selection}

Due to the poor regularity of load changes in MCDES, it is difficult to carry out active control, so the buffer intermediate cistern is selected for random real-time control.

The operating time of the thermochemical power generation and heating system can be extended, which is directly related to the selected gas storage tank. In order to save investment, a $50 \mathrm{~m}^{3}$ gas storage tank can be used to extend the operation for 2 hours. 


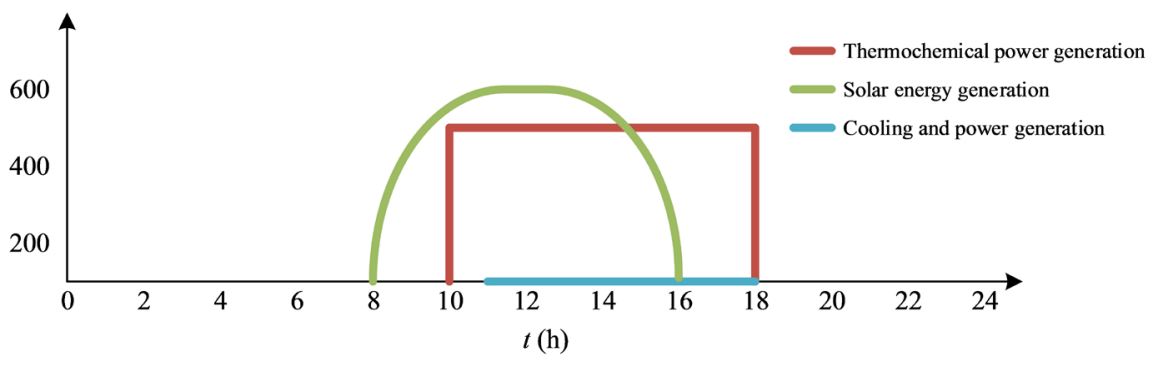

Figure 4. Power generation situation of DES project in winter.

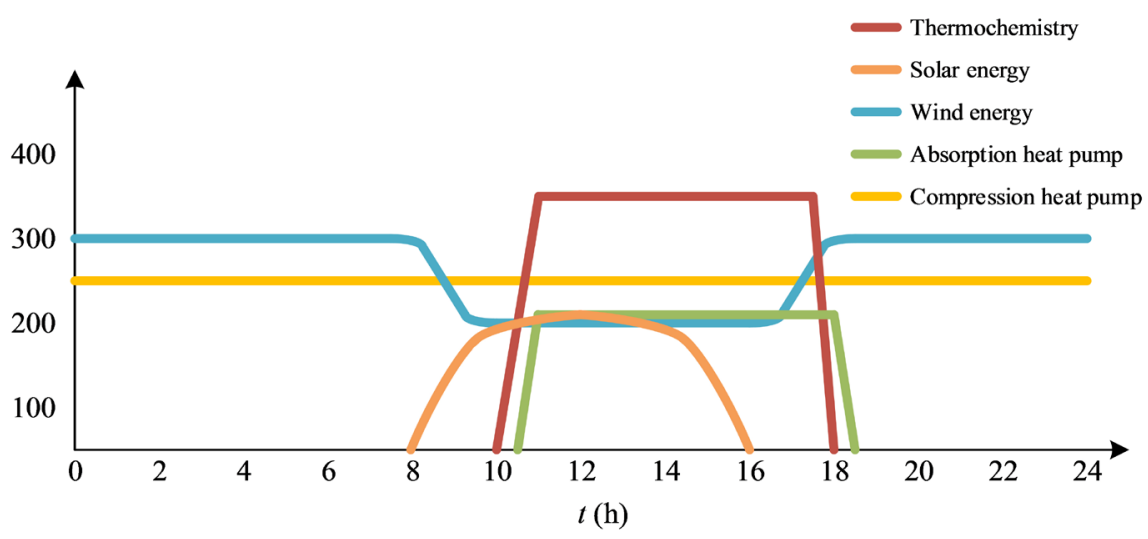

Figure 5. Heating situation of DES project in winter.

From the equipment operation principle and heating diagram, if the four-stage compression heat pump unit is driven by photovoltaic power, it can only operate during the day. Therefore, aiming at improving the controllability, an electric drive method is used to increase the temperature.

Since the renewable energy supply in this system cannot fully meet the peak load of the hotel, the system must be connected to the grid. Once the load increases, mains electricity is still needed to supply power and to drive the electric boiler to supply heat.

\subsection{Real-Time Power Control}

The multi-energy complementary distributed energy system adopts the grid-connected operation mode without power injection. Under normal circumstances, after meeting the electricity demand of the hotel, the surplus electric energy is first sent to the electricity storage part, whose capacity is small. In addition, hot water electric boilers or compression heat pump units can be started to use other surplus electricity for heating.

\subsection{Real-Time Thermal Control}

There are many links and equipment for distributed heating in this system, which are generally collected in the buffer intermediate cistern to supply heat to the hotel. When the temperature of the intermediate cistern is too high, hot water can be sent to $3000 \mathrm{~m}^{3}$ cross-season thermal storage cistern. When the tem- 
perature of the intermediate cistern is too low and the distributed energy supply is unable to provide power, the hot water of the cross-season thermal storage cistern can be drawn for supplementary heating. The cross-season thermal storage cistern is a layered pool with an upper water temperature of $50^{\circ} \mathrm{C}$, which can meet the heat demand of users such as hotels.

\section{Conclusion}

This multi-energy complementary distributed energy system performs real-time measurement and control of all energy supply equipment to analyze the operating characteristics and data. For the stable, reliable, intelligent and efficient operation of the system, a new type of active control strategy is proposed and an overall system scheme suitable for towns is developed, which provides technical support for the grid-connected operation in the future.

\section{Acknowledgements}

This work was supported by National Key Research and Development Program 2018 YFB0905105.

\section{Conflicts of Interest}

The authors declare no conflicts of interest regarding the publication of this paper.

\section{References}

[1] Yu, X.D., Xu, X.D., Chen, S.Y., Wu, J.Z. and Jia, H.J. (2016) A Brief Review to Integrated Energy System and Energy Internet. Transactions of China Electrotechnical Society, 31, 1-13.

[2] Quelhas, A., Gil, E., McCalley, J.D. and Ryan, S.M. (2007) A Multiperiod Generalized Network Flow Model of the U.S. Integrated Energy System: Part I-Model Description. IEEE Transactions on Power Systems, 22, 829-836. https://doi.org/10.1109/TPWRS.2007.894844

[3] Lund, H. and Münster, E. (2006) Integrated Energy Systems and Local Energy Markets. Energy Policy, 34, 1152-1160. https://doi.org/10.1016/j.enpol.2004.10.004

[4] Zeng, M., Liu, Y.X., Zhou, P.C., Wang, Y.Q. and Hou, M.X. (2018) Review and Prospects of Integrated Energy System Modeling and Benefit Evaluation. Power System Technology, 42, 1697-1708.

[5] Jia, H.J., Wang, D., Xu, X.D. and Yu, X.D. (2015) Research on Some Key Problems Related to Integrated Energy Systems. Automation of Electric Power Systems, 39, 198-207.

[6] Ai, Q. and Hao, R. (2018) Key Technologies and Challenges for Multi-Energy Complementarity and Optimization of Integrated Energy System. Automation of Electric Power Systems, 42, 1-8.

[7] Wu, J.Z. (2016) Drivers and State-of-the-Art of Integrated Energy Systems in Europe. Automation of Electric Power Systems, 40, 1-7.

[8] Zhang, Y.W., et al. (2014) Development and Experiences of Smart Grid Projects in Europe. Power System Technology, 38, 1717-1723. 
[9] Han, Y., et al. (2018) Research Status and Prospect of Key Technologies for Coordinated Control of Multi-Energy Synergic Integrated Energy Systems. Electric Power Construction, 39, 81-87.

[10] Huang, R.L., Pu, T.J., Liu, K.W., Yang, Z.Y. and Chen, N.S. (2015) Design of Hierarchy and Functions of Regional Energy Internet and Its Demonstration Applications. Automation of Electric Power Systems, 39, 26-33.

[11] Panwar, N.L., Kothari, R. and Tyagi, V.V. (2012) Thermo Chemical Conversion of Biomass-Eco Friendly Energy Routes. Renewable and Sustainable Energy Reviews, 16, 1801-1816. https://doi.org/10.1016/j.rser.2012.01.024

[12] Qu, L., Ouyang, B., Yuan, Z.C. and Zeng, R. (2019) Steady-State Power Flow Analysis of Cold-Thermal-Electric Integrated Energy System Based on Unified Power Flow Model. Energies, 12, 4455. https://doi.org/10.3390/en12234455 